\title{
A Review of New Drug Innovation - Emerging Challenges And Mitigation Strategies
}

\author{
Samrat Sisodia ${ }^{1}$ \\ ${ }^{\prime}$ (UGSM - Monarch University, Zug, Switzerland)
}

\begin{abstract}
The present paper reviews trends in the development and approval of new drugs. The pharmaceutical industry continues to face the problems of high costs of new drug development, FDA's regulatory regime, and competition from generic drugs. At the same time, consumers' expectations regarding drug efficacy and safety have continued to increase. This explains why it has become increasingly harder for drug firms to invent new molecules during the last three decades. A few of the resolutions to these problems include strategic drug development data generation, lifecycle planning for a new molecular entity and mergers and acquisitions involving biotechnology and pharmaceutical companies. Moreover, cooperation amongst FDA's review division and industry is not at desired level to seek development of new safety and efficacy models for enhance productivity in the industry..
\end{abstract}

KEYWORDS: Drug Development, FDA, New Molecular Entities, Regulatory Strategies, Trends in New Drug Development

\section{INTRODUCTION}

Pharmaceutical companies, both large and small, have in recent years been encountering numerous challenges over the past decade. The rate innovation has gone down. This is attributed partly to a rapid increase in the cost of new drug development. Some of the other factors that may have contributed to this situation include high attrition rate during pre-clinical, lack of efficacy during the clinical phase, competition from generic drugs and barriers imposed by the Food and Drug Administration (FDA). The objective of the present paper is to review some of the challenges currently confronted by the pharmaceutical industry and avenues to mitigate these challenges. An analysis of drug approvals during the last three decades is made to determine whether a decline in new drug development has indeed occurred. The paper also examines the issue of new drug development. The other issues that this paper investigates include rising competition from generic drugs, FDA regulations, difficulties in inventing new molecules by pharmaceutical companies, and an emerging trend towards preference for biologic drugs.

\section{EMERGING CHALLENGES IN NEW DRUG DEVELOPMENT}

This section is going to discuss some of the challenges that investigators and manufacturers face in bringing new drugs to market. One of the major hurdle is the number of compounds that must be studied in order to get one new drug commercially available. In the discovery phase, scientist may start with 5,000 to 10,000 different compounds of which only about 250 make their way into the pre-clinical testing to the animal studies and laboratory studies [1]. Of those 250 that enter the pre-clinical testing, only about five are going to eventually be studied in the clinical trials. Throughout the three phases of clinical trials the company is in constant communication with the FDA and at the end submits the NDA, where only about one of those five drugs will ultimately be approved for use in humans [2].Elimination of such higher number of drug candidates from clinical phase points towards a greater concern, especially considering the amount of monetary resources involved required executing phase III studies [3]. It is found that lack of efficacy, or lack of effectiveness, is the leading reason for drugs not making it through three phases of clinical testing [4]. This is surprising and contrary to the perception of drug being unsafe or the side effect profile might be the biggest driver. Factually, it is lack of efficacy that more than half of the new drugs that enter Phase III clinical testing over half of those drugs will fail because they are not able to demonstrate the effectiveness for the reason for which it was developed.To have an extensive comprehension of some of the challenges in developing new drugs, cumulative approvals of new drugs over the last two decades were observed. As shown in Fig 1, cumulative approvals of new drugs has been fairly steady from years of 1990 through 2008 i.e. approximately 21 NDA approvals a year [5]. However, examining this a little more closely, it reveals that a lot of those new drugs that have been approved are similar to existing drugs on the market [5]. So a different way of viewing at this is to estimate the number of NMEs, or the number of new molecular entities that possess different mechanisms of action. NMEs are considered to be 
new drugs classes, or truly innovative drugs not available prior to the previous year [6]. Interestingly number of NMEs has diminished considerably in the last several years. From 1994 to 2004 the number of NMEs is at its lowest, and this is a concern for most researchers as we need not only new drugs, but we need new drugs that are better than existing therapies or work in ways that are different from existing therapies [7].

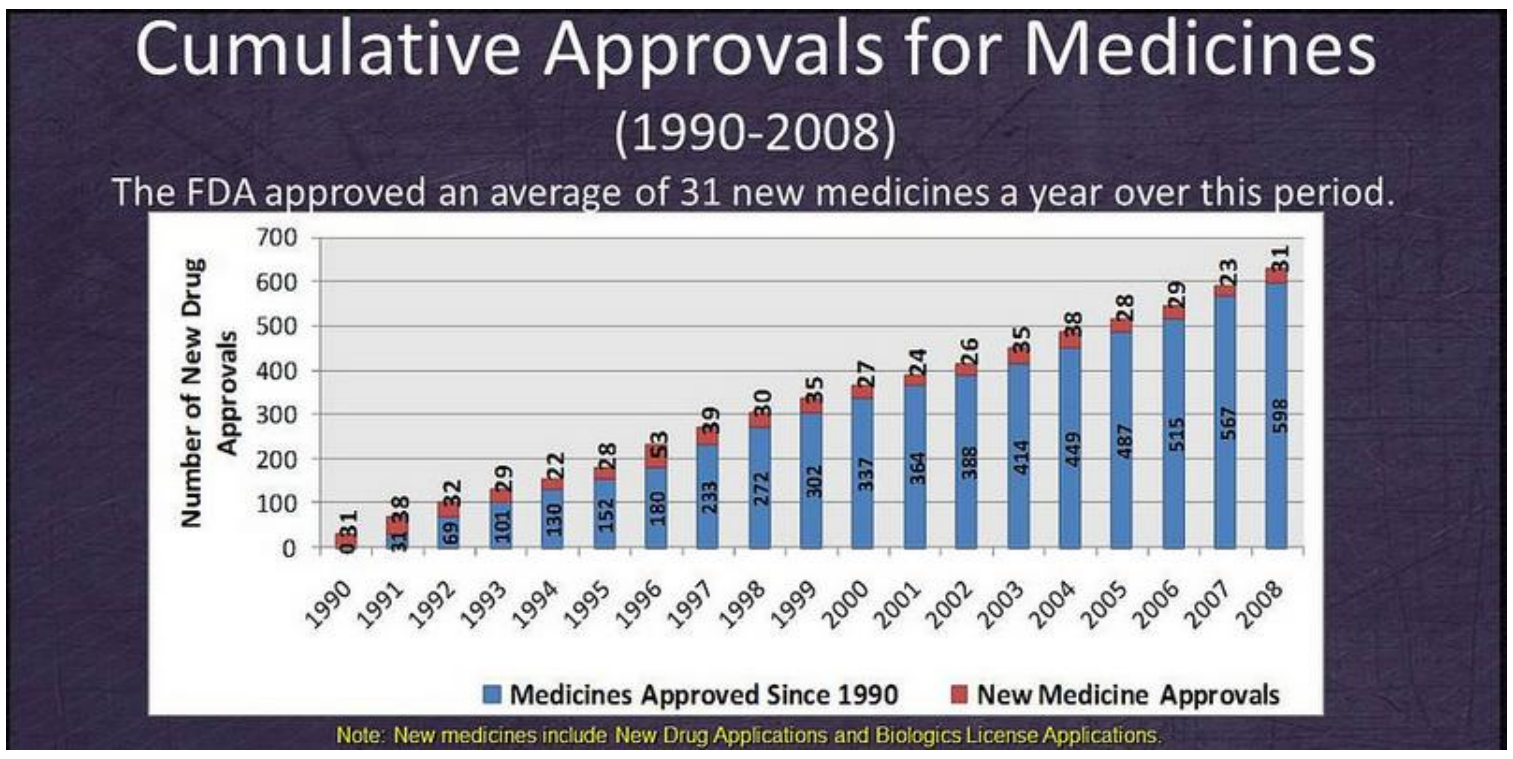

Figure 1: Cumulative NDA/BLA Approvals 1990-2008; Source: FDA, PhRMA and Pink Sheet, 2013

Now in contrast to the declining number of NMEs that had been approved, there is an exponential increase from 1994 to 2004 in drug expenditures that are responsible for developing these new drugs. In Fig 2 below, Hoekema (2008) compared R\&D expenses over 1994-2004 and number NME approved. Year 2004 represents twenty year low in the introduction of NME worldwide [8].

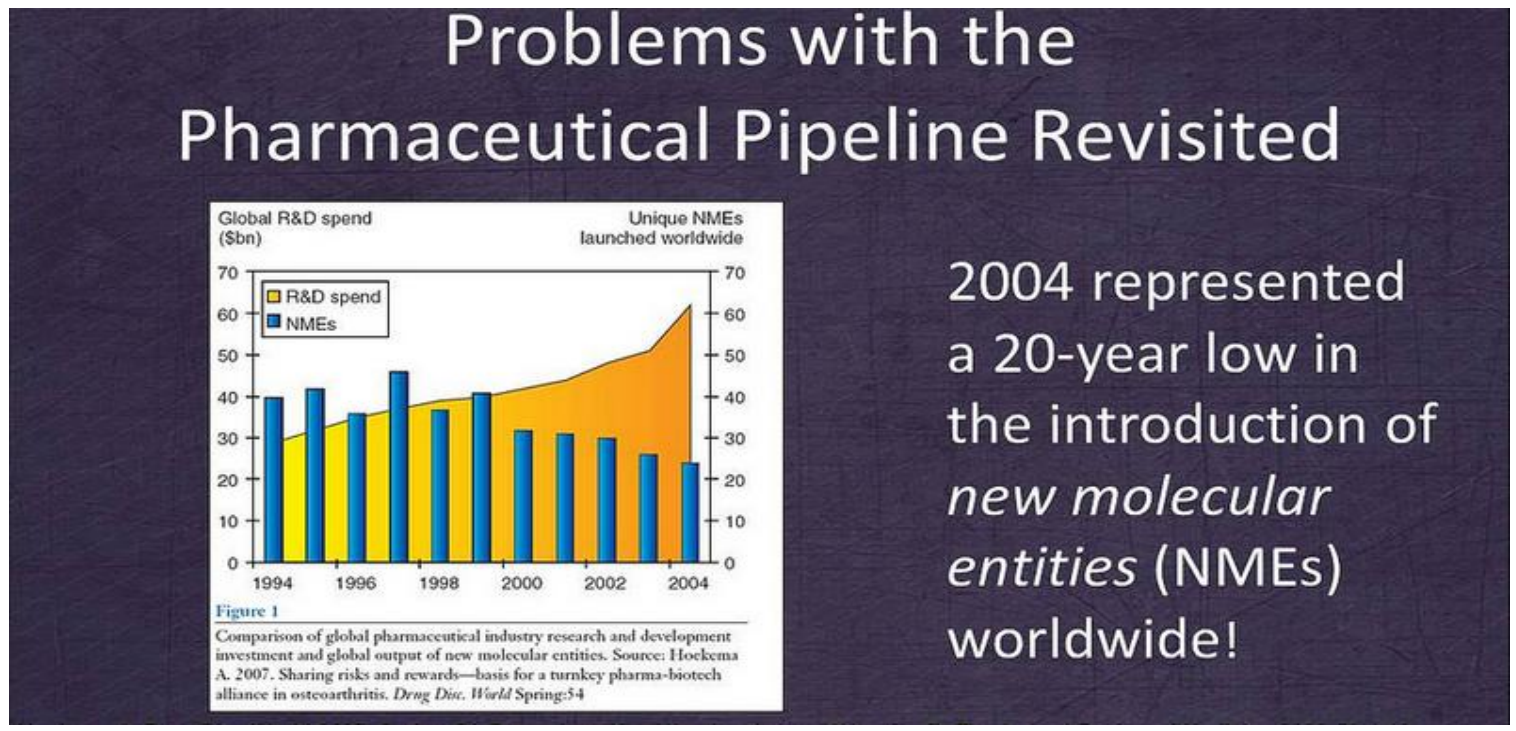

Figure 2: Drug Development R\&D Expenses; Source: Hoekema, 2008

Another challenge faced by current drug development is the difference in the success rate for different types of products in development. For example and as described in Fig 3, if a product is a systemic antiinfective, then the success rate is about $42 \%$, however if a new product is for gastrointestinal disease or a metabolic drug, the success rate is only about $10 \%$ to $12 \%$, which indicates towards a lot of variability in terms of the type of drugs that are being approved [9]. 


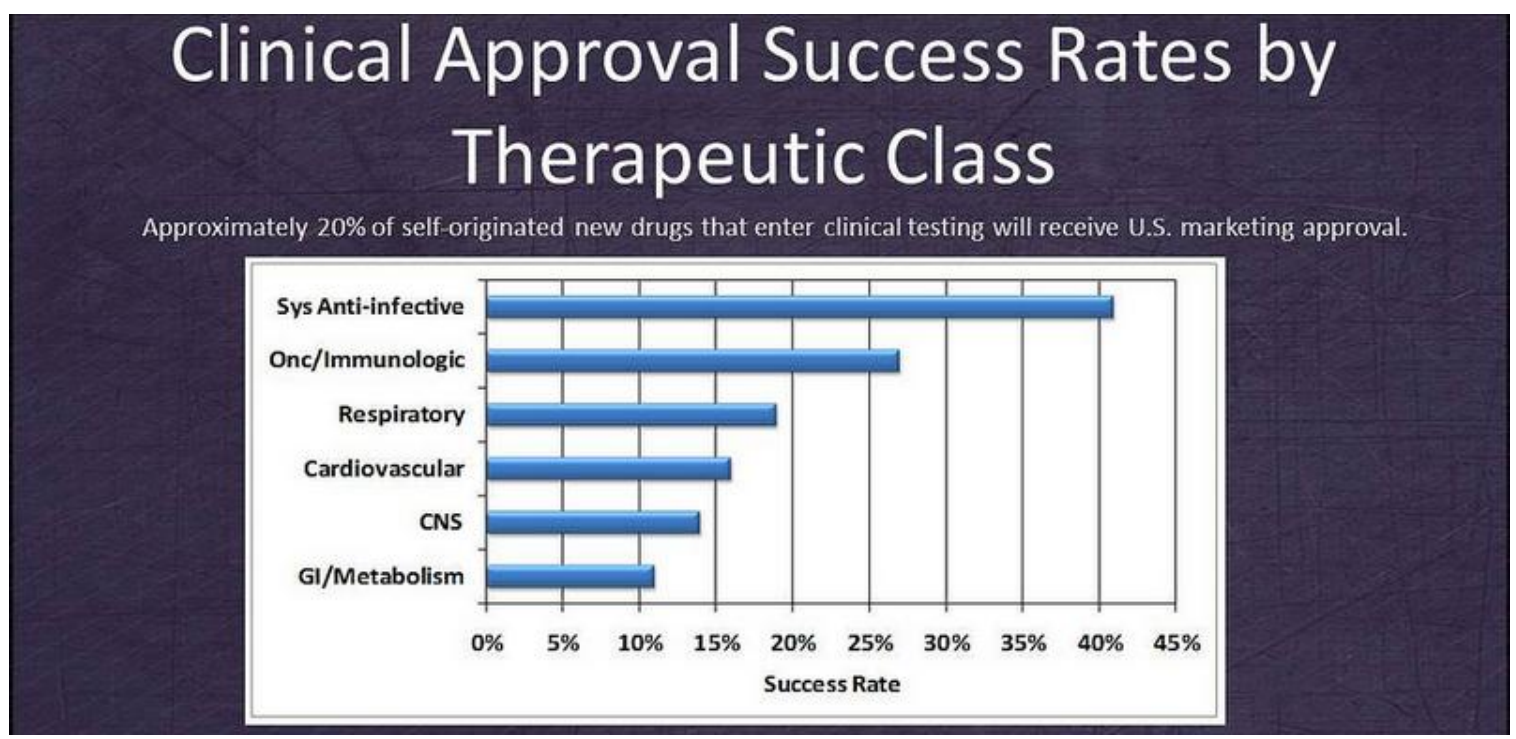

Figure 3: Differences in NDA Approvals by Therapeutic Class; Source: Tufts, 2005

Putting increase in R\&D cost drives that point home a little more. The cost to develop new drugs in 1979 was approximately $\$ 100$ million, whereas by 1991 , that cost was about $\$ 300$ million [10]. In the year 2000 , it went up to $\$ 800$ million, and in 2005 , it was $\$ 1.3$ billion. Current new drug development cost is around $\$ 1.8$ billion to $\$ 2$ billion [11]. See Fig 4 for the increase in $R \& D$ cost over the years.

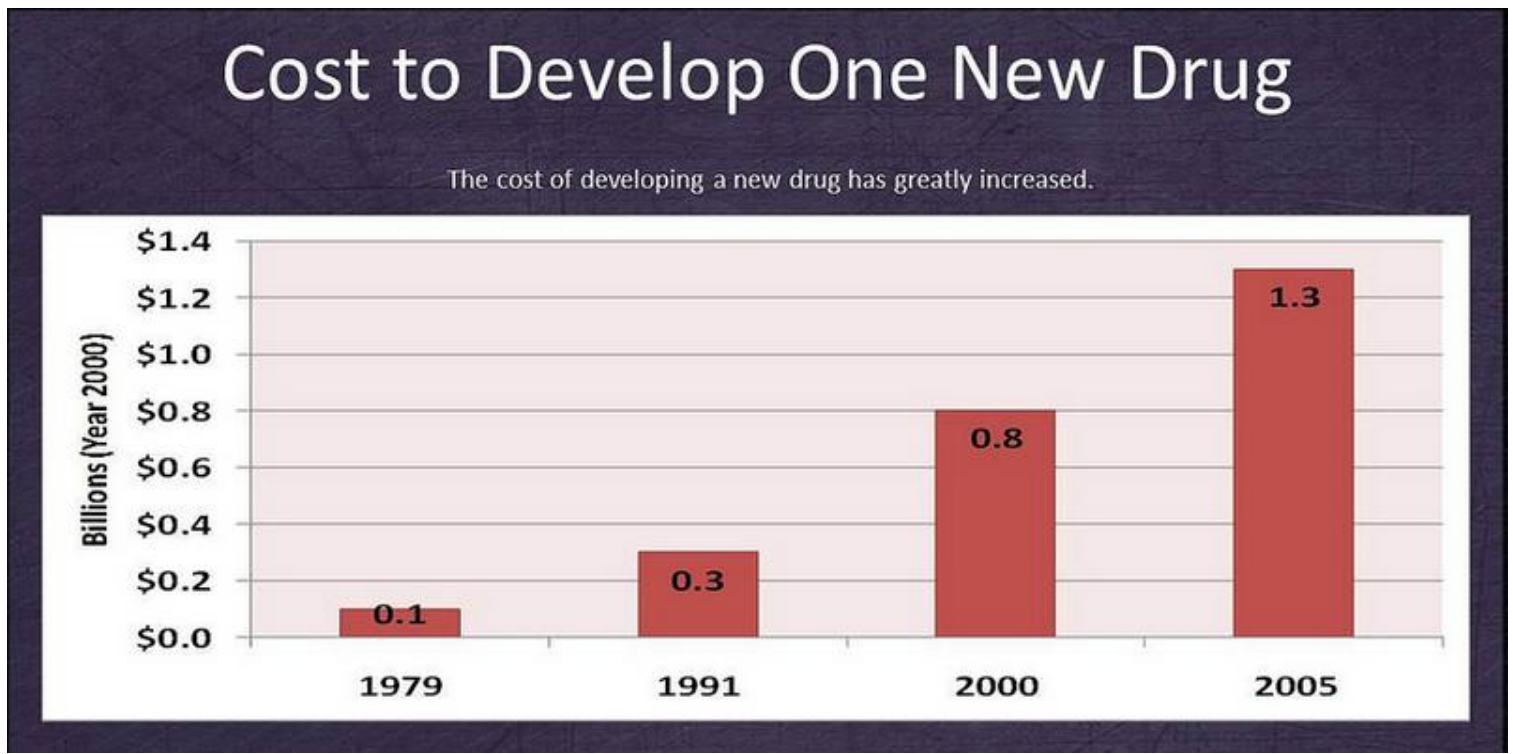

Figure 4: Cost of Drug Development 1980-2005; Source: DiMasi, Hansen, Grabowski, 2003

Although sales of new drug should bring back value, not all the new drugs are able to recoup the development cost. In the Fig 5 below drugs are grouped in tenths of lifetime sales, the category 1 represents the top tenth in terms of the highest grossing drugs that have been developed. Medications in this category earned about $\$ 1.8$ billion apiece on average between the period of 1990 to 1994 [12]. Drugs in category 2 also earned quite a bit of money too. Drugs categories 1 and 2, were able to exceed R\&D investment threshold (indicated by the redline) of that time, which was about $\$ 500$ million [13]. Only those top $20 \%$ of drugs in categories 1 and 2 were able to exceed that investment threshold. The rest eight categories, they all fail to exceed that threshold. It really means that companies are particularly interested in developing those medications that are in categories 1 and 2 and in fact, it has a special name, called a blockbuster drug [13]. 


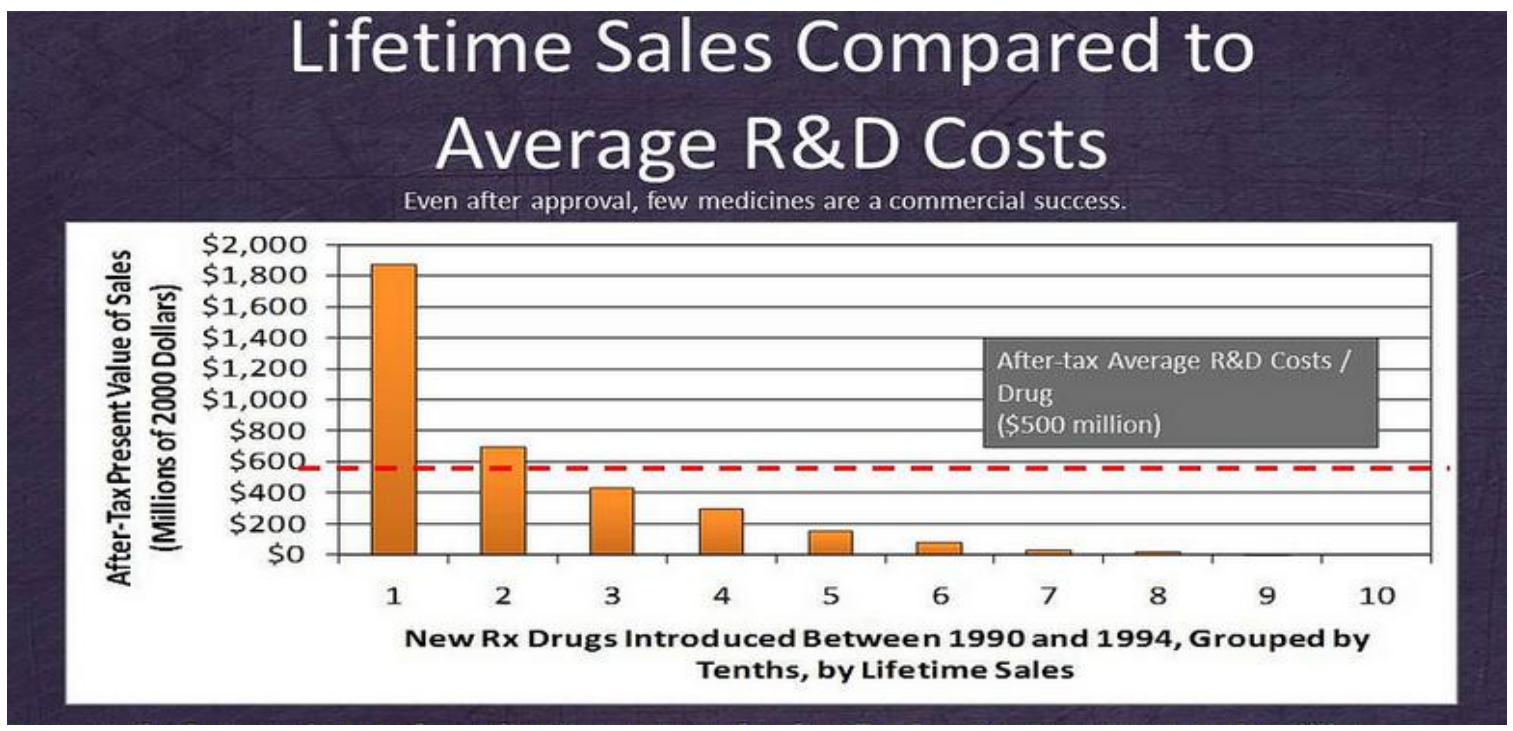

Figure 5: Lifetime Sales vs. Average R\&D Costs; Source: DiMasi, Vernon, Grabowski, 2007

Some of the other challenges that are involved in developing drugs have to do with the complexity of the clinical trials that are necessary to gain approval for those drugs and here we have five different dimensions of clinical trials that have changed over the years. The first one has to do with the number of unique procedures that a volunteer must undergo to be in a clinical trial, from 1999 to 2005, the number of unique procedures increased by $46 \%$ [14]. If we look at the total number of procedures that are required per protocol, a similar pattern is observed where again the volunteer is being subject to undergo more procedures than they have been in the past. Also, there is an increase in the workload of the clinical staff which helps to perform $\mathrm{f}$ these clinical trials. The length of the clinical trials from 1999 to 2005 has almost doubled in terms of the number of days that a patient would be in the trial [14]. Looking across 1999 to 2005, clinical trial enrollment rate has dropped by $21 \%$, and burdensome commitments, procedures and in-flexibilities during trail are main reasons behind this drop [14]. From 1999 to 2005, the retention rate has also declined dramatically in these clinical trials. Fig 6 summarizes some of the complexities observed in clinical trials over the years.

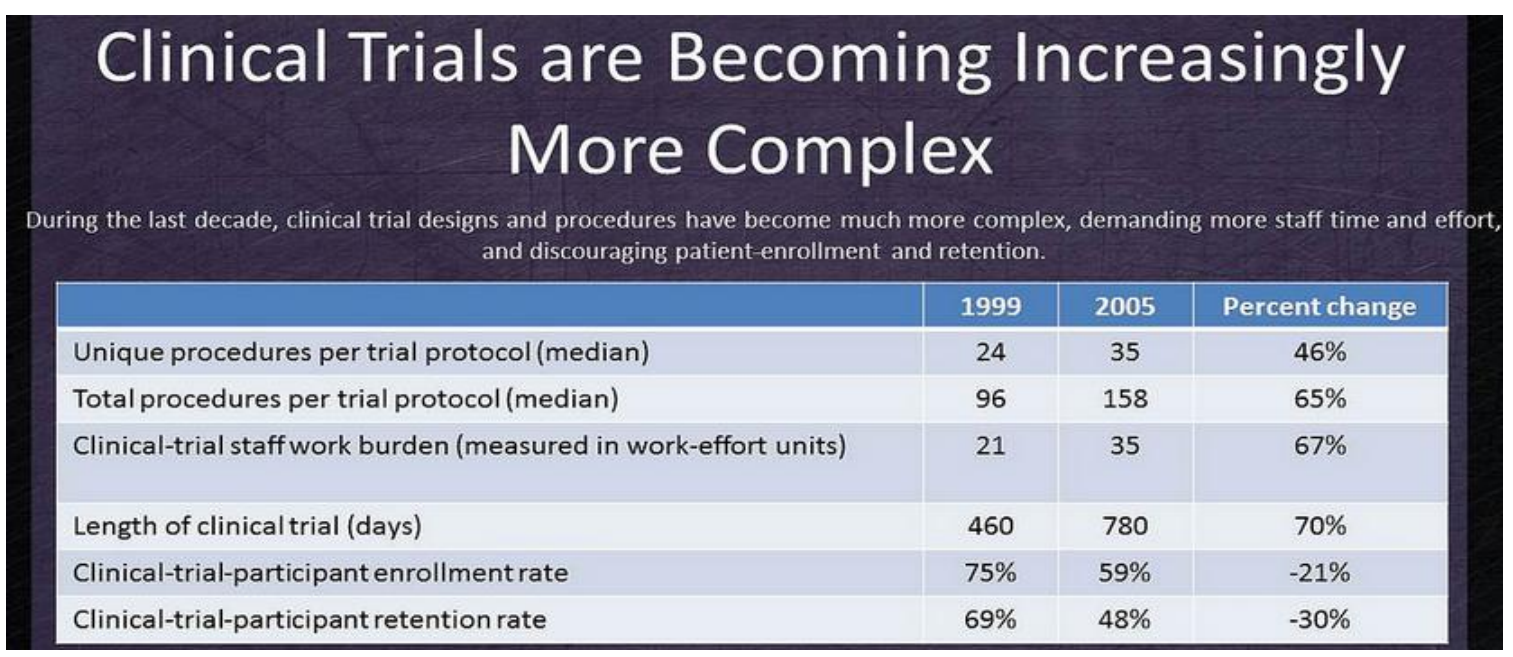

Figure 6: Increasing Complexities in Clinical Trials; Source: Tufts, 2008

One of the reasons why innovation in the pharmaceutical industry is on a decline is the regulatory framework imposed by FDA. As Abrams (2012) points out, FDA regulatory scientists have been reluctant to work together with industry scientists with a view to promote innovation. The synergy is lacking because these two entities are not working together to safeguard public health while at the same time promoting innovation in the industry [15].Carpenter (2002) adds that the FDA has been criticized for being reluctant to approve some drugs while being very quick to approve others. According to Carpenter (2002) the process of reviewing drug is akin to the bureaucratic learning process. 
The FDA is to blame for shifting waiting costs on a case-specific basis. However, this tendency is being influenced by firms, politicians, the media, and disease-specific organizations [2, 16, 17, \&18]. Nevertheless, Carpenter (2012) also observes that, on average, FDA review times have been decreasing. The FDA's move towards the introduction of strict guidelines may have been greatly influenced by a trend in which societal expectations point towards the need for a higher level of drug efficacy and safety. In the context of this expectation and a downward trend in productivity, it is not surprising that the level of innovation in the pharmaceutical industry has continued to decline. This view is shared by Woodcock (2012) who argues that the introduction of the Critical Path Initiative has greatly contributed to this phenomenon. This is also ironic because the intent of this initiative was to modernize drug development by incorporating advanced imaging technologies and genomics into the process [20]. Another major hurdle faced by new drug development is the competition from generic and 505(b)(2) application holders. With the slowdown in new drug development, it is very challenging for new drug manufacturers to maintain products lifecycle planning with constant pressure from generic manufacturers. Another dimension relates to a rapid increase the number of generic entrants especially in the case of drugs with larger sales and shorter periods of market exclusivity [20]. Moreover, competition relates to a phenomenon in which "blockbuster" drugs whose annual sales exceed $\$ 1$ billion continue to experience a reduction in periods of market exclusivity [21]. According to Frank (2007), generic drugs constitute 63 percent of all prescriptions for drugs in the US. These drugs pose a threat of competition because they are sold at lower prices. By buying these drugs, consumers are able to save billions of dollars annually [22]. This means that the pharmaceutical industry is going through a challenging time especially considering that well-known drugs, including Fosamax (aledronate) and Imitrex (sumatriptan) lost their patent protection between 2007 and 2010 [22].

\section{MITIGATION OF CHALLENGES OF NEW DRUG DEVELOPMENT}

Organizations carrying new drug development have to recognize the change in the current environment and brace it with creating strategies which can counter challenges of modern times. A successful new drug development company not only launches new drug products in the shortest time but requires minimal data to support its approval from the agency.Today, new drug development more than ever requires creative regulatory strategies in order to minimize data burden for approval and to maximize the lifecycle planning of the new drug. Apart from defining data requirements for all phases of drug development, today regulatory strategies are immensely important to secure data strategies which help distinguishing new drug from generic competition and in some cases makes it very hard future generics copy the new drugs. Examples of such strategies include, 1. securing distinct plasma pharmacokinetic profile, 2. evaluation of potential produrgs, polymorphs and salt forms etc. of the active moiety, 3. distinct formulation or dosage form. One great thing that has happened in terms of drug development is the passage of the Orphan Drug Products Act in 1983 [23] (Grabowski H. G., 2004). The Act provided incentives to drug manufacturers to develop drugs for rare diseases. A disease is recognized to be rare if fewer than 200,000 people in the United States have that disease. Without these incentives, companies may be reluctant to develop such drugs because there is not going to be a very large market share, but with the passage of this Orphan Drug Act, there were three incentives in particular that have helped to spur the development of these types of drugs [19]. The initial example has to do with patent exclusivity to sell that type of medication for use in that rare disease for the duration of seven years. There is also a special grant program where companies can seek government funding for clinical trials. Finally, there are tax credits that the company receives if they developed one of these products. This program has been immensely successful, prior to 1983 , there were only 10 orphan drugs brought to market, after 1983, there have been more than 250 orphan drugs brought to market [21].

Another thing that has been approved to overcome some of the challenges of developing drugs is the Prescription Drug User Fee Act of 1992. This particular act required pharmaceutical manufacturers to pay a fee to the Food and Drug Administration in order to review its new drug application [24]. This user fee enables FDA to hire trained professionals to review applications and have more resources at the disposal. With additional resources and workforce, FDA is able to review the application more quickly, in a period of only 6 to 12 months [25].Finally, this is a very recent development which happened in year 2013, it is the idea of having breakthrough therapies. This is essentially a new classification of drugs that are very beneficial because it really reduces the amount of time that it takes to bring one of these new drugs to market. Clearly, this requires a lot of close communication between FDA and the manufacturer to assure that the studies are designed well and that the data indicate that in fact, the drug is safe and effective, but it really does shorten the time to approval. There are three drugs now that have been granted breakthrough status by the FDA [26]. Two of those drugs were approved this year for cystic fibrosis. There are several others that are waiting for this type of review, in fact, 
there are 18 new drugs currently that have been granted this breakthrough status and are going through the Phase 1 process and will hopefully be approved for use in the United States very shortly [26].

\section{CONCLUSION}

In conclusion, the rate at which new drugs are being developed is still regarded as the most critical measure of innovation in the pharmaceutical industry. This explains why many researchers have decried the slowdown of new drug approvals during the past three decades. During this time, competition from generic drugs, high cost of new drug development, and obstacles posed by FDA regulations have been the biggest challenges in efforts to increase the level of new drug development.One of the ways of overcoming these challenges is for drug firms to bridge the existing gaps in the innovation processes. Partnerships in innovation can also help boost productivity while reducing costs. Pharmaceutical companies should also look into ways of diversifying their options as a way of building a balanced research portfolio that will ultimately lead to persistent discovery of new drug molecules. Moreover, FDA scientists should work in cooperation with industry researchers with a view to improve efficacy and enhance productivity in the industry. Finally, more mergers and acquisitions involving biotechnology and pharmaceutical companies should be pursued. This will lead to longterm benefits across business segments and value chain components. These efforts should be made in the context of the contemporary trend in which biologic drugs are increasingly becoming dominant in the areas of drug discovery and innovation.

\section{REFERENCES}

[1] DiMasi et al., J. (1995). Research and Development Costs for New Drugs by Therapeutic Category: A Study of the U.S. Pharmaceutical Industry. PharmacoEconomics, 152-169.

[2] DiMasi, J. (2001). New drug development in the United States from 1963 to 1999. Clinical Pharmacology \& Therapeutics, 69(5), 286-296.

[3] DiMasi-4, J., \& Grabowski, H. (1995). R\&D Costs, Innovative Output, and Firm Size in the Pharmaceutical Industry. International Journal of the Economics of Business, 201-221.

[4] Grabowski-4, H. G., Vernon, J. M., \& DiMasi, J. (2002). Returns to R\&D on 1990s new drug introductions. PharmacoEconomics, 20 supplement 3: 1-29 (19).

[5] FDA-14, PhRMA, \& Sheet, P. (2009). New Drug Approval: 1991-2008 New Molecular Entities Approved. Washington, DC: CBO.

[6] Gassmann, O., \& Reepmeyer, G. (2005). Organizing Pharmaceutical Innovation: From Science-based Knowledge Creators to Drugoriented Knowledge Brokers. Creativity and Innovation Management, 14(3), 233-245.

[7] DiMasi, H. (2003). The price of innovation: New estimates of drug development costs. Journal of Health Economics, 22(2), 151-185.

[8] Hoekema, A. (2008). The Annual review of Medicine 2008. Drug Disc World, 59:1-12.

[9] Tuft. (2005). New Drugs entering clinical testing in top 10 firms jumped 52\% in 2003-05 - Impact report. Tuft Center for the Study of Drug Development.

[10] DiMasi, J., Hansen, R., \& Grabowski, H. (2003). The Price of Innovation: New Estimates of Drug Development Costs. Journal of Health Economics, 151-185.

[11] DiMasi, J. (2003). The economics of pharmaceutical innovation: Costs, risks, and returns. Bio Strategy Seminar Series, MIT Sloan School of Management.

[12] Dimasi, J., Hansen, R., Grabowski, H., \& Lasagna, L. (1995). Cost of innovation in thepharmaceutical industry. Journal of Health Economics, 10: 107-142.

[13] Vernon, DiMasi, \& Grabowski. (2007). The Cost of Biopharmaceutical R\&D; Is biotec Different? Managerial and decision Economics.

[14] Tufts. (2008). Growing Protocol Design Complexity Stresses Investigators, Volunteers - Impact Report . Tufts Center for the Study of Drug Development.

[15] Abrams, W. (2012). Is It Possible for FDA Regulatory Scientists and Industry Scientists to Work Together? Clinical Pharmacology \& Therapeutics, 91(3), 390-392.

[16] Carpenter1, D. (2002). Groups, the Media, Agency Waiting Costs, and FDA Drug Approval. American Journal of Political Science, 46(3), 490-505.

[17] Carpenter, D. (2004). The Political Economy Of FDA Drug Review: Processing, Politics, And Lessons For Policy. Health Affairs, 23(1), 52-63.

[18] Reichert, J. (2003). A guide to drug discovery: Trends in development and approval times for new therapeutics in the United States. Nature Reviews Drug Discovery, 2, 695-702.

[19] Woodcock, J. (2011). The FDA Critical Path Initiative and Its Influence on New Drug Development, Annual Review of Medicine. Washington, DC: FDA.

[20] Spellberg, B. (2004). Trends in Antimicrobial Drug Development: Implications for the Future. Clinical Infectious Diseases, 38(9), 1279-1286.

[21] Grabowski, H. (2007). Generic competition and market exclusivity periods in pharmaceuticals. Managerial and Decision Economics, 28(4), 491-502.

[22] Grabowski, H. G. (2004). Are the economics of pharmaceutical research and development changing? Productivity, patents and political pressures. PharmacoEconomics, 22(Suppl 2), 15-24.

[23] Frank, R. (2007). The Ongoing Regulation of Generic Drugs. New England Journal of Medicine, 357, 1993-1996

[24] Bogdanich, W. (1992). FDA enacts plan to speed process of drug approval. Wall Street Journal.

[25] Kaitin-2, K. (2003). The New Drug Approvals of 1999, 2000, and 2001: Drug Development Trends a Decade after Passage of the Prescription Drug User Fee Act of 1992. Therapeutic Innovation \& Regulatory Science, 37(4), 357-371.

[26] FDA. (2013). Retrieved from http://www.fda.gov/ForIndustry/UserFees/GenericDrugUserFees/ucm 337385.htm 